\title{
Does Binary Classification of Motivation Carry Weight (Note 1)
}

\author{
Donghong Liu $^{1 *} \&$ Zhu Shen ${ }^{1}$ \\ ${ }^{1}$ English Department, School of Foreign Languages, Central China Normal University, Wuhan, China \\ *Donghong Liu, E-mail: liudonghong19@ sina.com
}

\begin{abstract}
With the population of postgraduates increasing in China, their academic study has attracted the attention of second language acquisition researchers. But the research into postgraduates' motivation and autonomy is unfortunately scarce. This study explores the relationship between learning motivation and learner autonomy among English-major postgraduates based on the questionnaire administered to 117 participants. In view of the complicatedness of the postgraduates' academic study, both intrinsic motivation and extrinsic motivations were further divided into two types. The results show that: 1) four types of motivation differ significantly and the strongest is motivation for job; 2) although each type of motivation positively correlates with the perceived autonomy, yet only type of intrinsic motivation and one type of extrinsic motivation has predictive power for the perceived autonomy. It indicates that binary classification of motivation does not work well in predicting the postgraduates' perceived autonomy.
\end{abstract}

\section{Keywords}

learning motivation, perceived autonomy, English-major postgraduates

\section{Introduction}

Learning motivation and learner autonomy have captured the attention of scholars, researchers and teachers in second language acquisition. Learning motivation is defined as "an internal mechanism that instigates and sustains learning activities and orients them towards a certain goal" (Feng, 2010, p. 226). Different types and sub-types of motivation have been proposed, such as intrinsic-extrinsic motivation, integrative-instrumental motivation (Ellis, 1999; Ortega, 2009), motivation of achievement (Gao, 2003), motivation of self-realization and motivation of social needs (Wu \& Bao, 2013). The widely accepted is intrinsic-extrinsic motivation, a binary classification. However, using different ways to describe motivation, many researchers have interpreted the degree of motivation divergently and reported different results (Lin, 2008; Zhao \& Li, 2014).

Learner autonomy is another hot topic. Holec (1981) considers it as "the ability to take charge of one's own learning" (cited in Spratt et al., 2002, p. 249). Some studies of learner autonomy have investigated young learners (Wu, 2013), and more studies have focused on undergraduates (Tanaka, 2013; Navarro $\&$ Thornton, 2011; Noels, 2001; He et al., 2011). But the postgraduates have more complicated motivations than younger English learners and they perceive their autonomy in a different way. 
Nevertheless, the related research into such a learner group is not sufficient and the relationship between each type of motivation and perceived autonomy is still not clear. To fill the gap, this study was made to investigate the mutual influence on each other and the specific factors inside.

\section{Related Studies of the Relationship between Motivation and Autonomy}

Many researchers have studied the relationship between learning motivation and learner autonomy, and found that they are correlated (Spratt et al., 2002; He et al., 2011). Some studies confirmed the validity of L2 intrinsic motivation in predicting perceived competence and perceived autonomy (Noels, 2001; $\mathrm{Wu}, 2003)$. Ni (2010) concludes that there are mainly three views. One is motivation determination, that is, motivation determines autonomy; another view is autonomy determines motivation; the third view is mutual determination, that is, the two influence and promote each other. Investigating the influence of different types of motivation on learner autonomy, $\mathrm{Ni}$ (2010) found that the correlation between instrumental motivation and learner autonomy is stronger than that between integrative motivation and learner autonomy. As for intrinsic motivation, $\mathrm{Wu}$ (2013) found that the learners who had more positive perception of their autonomy were more likely to be intrinsically motivated in L2 learning. Hua (2009) discovered that intrinsic motivation has strong correlation with learner autonomy. $\mathrm{Li}$ and $\mathrm{Yu}(2008)$ found that both intrinsic and extrinsic motivation can effectively predict learner autonomy. Besides, the research of Gao (2003), Xu and Li (2014) shows that the motivation of achievement, as an extrinsic motivation, is negatively correlated with learner autonomy.

However, in all those studies the components of motivation are inconsistent due to their different focus and accordingly their results do not agree with one another. Moreover, according to Dornyei's (2009) theory, "ideal self" consists of both integrative motivation and instrumental motivation, and the two types of motivation entangle in the present globalization context in China (Qin \& Dai, 2013). Taking a binary classification of motivation and making comparison is likely to simplify the case. Therefore, new appropriate division and classification of motivation must be used in present Chinese context and the relationship between motivation and perceived autonomy should be studied freshly.

As the group of postgraduates expands in China, the researchers have begun to show interest in them. Some have studied the English-major postgraduates' academic study (Wu \& Yuan, 2012; Wu \& Bao, 2013; Wu, 2014). For example, Wu (2014) investigated it and found that it includes four factors: learner autonomy, critical thinking, learning motivation, and course and teaching evaluation. Hence, the English-major postgraduates' academic study is different from English-major undergraduates' and non-English major postgraduates'. It involves not just the learning and training of basic language skills but also the study of linguistic theories. Besides, research into English-major postgraduates is far from enough. 


\section{Research Design}

\subsection{Research Questions}

As mentioned above, many studies take a binary classification of motivation and the widely accepted is intrinsic-extrinsic motivation. Based on this classification, four types of motivation are probed in this study, with two types of intrinsic motivation and two extrinsic ones. The present study aims to answer the following questions:

1) Which is stronger, intrinsic motivation or extrinsic motivation? Do the four types of motivation have significant difference?

2) Does intrinsic/extrinsic motivation make a difference in relation to the perceived learner autonomy?

\subsection{Participants}

One hundred and seventeen English-major postgraduates in a normal university were involved in the study. Only the first- and second-year students were chosen since the third-year students were busy with their theses writing and job searching. The participants' age was mainly between 22 and 25 . Their orientations and population distribution were as follows: English linguistics: 49 (42\%), English literature: 40 (34\%), English translation and interpretation: 28 (24\%). They would be teachers in middle schools or primary schools. Most of them were practicing teaching in their spare time.

\subsection{Instruments}

Although many researchers have designed some valid scales measuring motivation and learner autonomy, yet most of them are directed at ESL undergraduates, high school and middle school students. Wu $(2012,2014)$ has done much research both solely and collaboratively into Chinese postgraduates' learning motivation and perceived learner autonomy, and her questionnaires are well acknowledged in China. So we took her questionnaires but modified slightly by deleting some items loosely related to motivation and autonomy. Finally, our questionnaire was a five-point Likert-type scale sequentially assigning values $1,2,3,4,5$ to options of "nearly $100 \%$ disagree", "more than $50 \%$ disagree", "50\% agree", "more than 50\% agree", "nearly 100\% agree". The whole questionnaire consisted of autonomy and motivation: autonomy questionnaire containing 25 items, and motivation questionnaire 14 items. The former included Thinking and judging ability (4 items: 13, 22, 23, 25), Self-confidence (4 items: 4, 12, 15, 19), Planning and monitoring (6 items: 1, 2, 3, 8, 21, 24), Problem solution ability (5 items: 6, 14, 16, 17, 18), Academic knowledge acquiring (6 items: 5, 7, 8, 9, 10, 19). The latter was made up of Motivation for major (4 items: 32, 33, 34, 37), Motivation for excellence (4 items: 26, 27, 30, 31), Motivation for other people (3 items: 28, 29, 39) and Motivation for job (3 items: $35,36,38)$. Since intrinsic motivation refers to "doing something because it is inherently interesting or enjoyable" and extrinsic motivation refers to "doing something because it leads to a separable outcome" (Ryan \& Deci, 2000, p. 55), motivation for major and motivation for excellence are intrinsic while motivation for other people and motivation for job are extrinsic.

One hundred and thirty copies were distributed and 117 were collected. Analyzed by SPSS 19.0, the motivation and the autonomy questionnaires displayed high Cronbach $\alpha$ value respectively $(0.954$ and 
0.897), which indicated that the items in both questionnaires were consistent and further analysis could be carried out.

\section{Results}

4.1 Learning Motivation and Learner Autonomy

Table 1. Descriptive Statistics of Learning Motivation

\begin{tabular}{cllllll}
\hline & $\mathrm{N}$ & $\mathrm{MIN}$ & $\mathrm{MAX}$ & $\mathrm{Mean}$ & $\mathrm{SD}$ \\
\hline Intrinsic motivation & Motivation for major & 117 & 1.00 & 5.00 & 3.214 & .729 \\
& Motivation for excellence & 117 & 1.00 & 5.00 & 3.438 & .782 \\
Extrinsic motivation & Motivation for other people & 117 & 1.00 & 5.00 & 3.396 & .811 \\
\cline { 2 - 5 } & Motivation for job & 117 & 1.00 & 5.00 & $\mathbf{3 . 6 5 2}$ & .794 \\
Total & 117 & 1.00 & 5.00 & 3.481 & .650 \\
\hline
\end{tabular}

Table 1 shows that extrinsic motivation is stronger than intrinsic motivation $(7.048>6.652)$. The mean scores of all of the types are above the average 3 points but below 4 points, with the highest being motivation for job and the lowest motivation for major. The standard deviations approximate as well as the mean scores. However, submitted to Friedman test, the four types of motivation display significant difference with the $\mathrm{X}^{2}$ value $207.044(\mathrm{p}=0.000)$.

Perceived autonomy displays quite similar tendency in its five variables in Table 2, with more approximate standard deviation than in Table 1. The score of self-confidence is the highest of the five variables. The result of Friedman test shows significant difference $\left(X^{2}=368.890, p=0.000\right)$. In addition, the two tables demonstrate the difference in the maximum point, with Table 2 showing lower points. It indicates that different from motivation assessment, the postgraduates were less certain about their ability or more critical in assessing their ability.

Table 2. Descriptive Statistics of Learner Autonomy

\begin{tabular}{llllll}
\hline & N & MIN & MAX & Mean & SD \\
\hline Thinking and judging ability & 117 & 1.00 & 4.75 & 3.227 & .768 \\
Self-confidence & 117 & 1.25 & 5.00 & $\mathbf{3 . 3 5 9}$ & .759 \\
Planning and monitoring & 117 & 2.00 & 5.00 & 3.241 & .680 \\
Problem solution ability & 117 & 1.40 & 4.80 & 3.299 & .674 \\
Academic knowledge acquiring & 117 & 1.67 & 4.83 & 3.296 & .695 \\
Total & 117 & 1.77 & 4.92 & 3.288 & .644 \\
\hline
\end{tabular}




\subsection{Correlation and Regression Analysis Results}

To explore the relationship between learning motivation and learner autonomy, the correlation among the two and their types were scrutinized. The results are shown in Table 3.

Table 3. Correlation Matrix among Motivation, Autonomy and Their Types

\begin{tabular}{lllllll}
\hline & A1 & A2 & A3 & A4 & A5 & Total Autonomy \\
\hline Motivation for major & $0.486^{* *}$ & $0.498^{* *}$ & $0.469^{* *}$ & $0.446^{* *}$ & $0.419^{* *}$ & $0.471^{* *}$ \\
Motivation for other people & $0.438^{* *}$ & $0.556^{* *}$ & $0.409^{* *}$ & $0.417^{* *}$ & $0.350^{* *}$ & $0.405^{* *}$ \\
Motivation for job & $0.507^{* *}$ & $0.552^{* * *}$ & $0.455^{* *}$ & $0.464^{* *}$ & $0.520^{* *}$ & $\mathbf{0 . 5 0 9}$ \\
Motivation for excellence & $0.457^{* *}$ & $\mathbf{0 . 5 9 6}^{* *}$ & $0.448^{* *}$ & $0.410^{* *}$ & $0.403^{* *}$ & $0.465^{* *}$ \\
Total Motivation & $0.576^{* *}$ & $\mathbf{0 . 6 6 5}^{* *}$ & $0.549^{* *}$ & $0.537^{* *}$ & $0.537^{* *}$ & $\mathbf{0 . 5 7 9}^{* *}$ \\
\hline
\end{tabular}

$* * \mathrm{p}<.01$.

Notes: A1 = Thinking and judging ability; A2 = Self-confidence; A 3 = Planning and monitoring ability; A4 = Problem solving ability; A5 = Academic knowledge acquiring.

From Table 3, it can be seen that learning motivation and learner autonomy are positively correlated (0.579). Of all types of motivation, motivation for job is the most strongly correlated with learner autonomy (0.509). Of all types of learner autonomy, self-confidence is the most strongly correlated with learning motivation (0.665). Besides, among the types of learning motivation and learner autonomy, the correlation coefficient between self-confidence and motivation for excellence is the highest (0.596). Generally speaking, all of the correlation coefficients are above average level 0.40 except that between motivation for other people and academic knowledge acquiring (0.350). Such correlation coefficients indicate that the two variables are moderately correlated according to Connolly and Sluckin (1957).

In order to further examine the relationship between learning motivation and learner autonomy and find out affecting variables, regression analyses were made in two directions, with learning motivation and learner autonomy as dependent variable respectively.

Table 4. Multiple Step-Wise Regression Analysis of Motivation on Autonomy (1)

\begin{tabular}{lllllll}
\hline Model & $\mathrm{R}$ & $\mathrm{R}^{2}$ & Adjusted $^{2}$ & Standard Error & $\mathrm{F}$ & Sig. \\
\hline 1 & $0.509^{\mathrm{a}}$ & 0.259 & 0.252 & 0.557 & 40.135 & 0.000 \\
2 & $0.561^{\mathrm{b}}$ & 0.314 & 0.302 & 0.538 & 9.224 & 0.003 \\
\hline
\end{tabular}

a. Predictors: (constant), Motivation for job.

b. Predictors: (constant), Motivation for job, Motivation for excellence. 
Table 5. Multiple Regression Analysis of Motivation on Autonomy (2)

\begin{tabular}{|c|c|c|c|c|c|c|c|c|}
\hline \multirow{2}{*}{\multicolumn{2}{|c|}{ Model }} & \multicolumn{2}{|c|}{ Unstd coefficients } & \multicolumn{2}{|c|}{ Std coefficients } & \multirow[b]{2}{*}{ Sig. } & \multicolumn{2}{|c|}{ Collinearity statistics } \\
\hline & & B & Std errors & $\beta$ & $\mathrm{t}$ & & Tolerance & VIF \\
\hline \multirow[t]{2}{*}{1} & (constant) & 1.782 & 0.243 & & 7.331 & 0.000 & & \\
\hline & Motivation for job & 0.412 & 0.065 & 0.509 & 6.335 & 0.000 & 1.000 & 1.000 \\
\hline \multirow[t]{3}{*}{2} & (constant) & 1.426 & 0.263 & & 5.428 & 0.000 & & \\
\hline & Motivation for job & 0.296 & 0.074 & 0.366 & 4.028 & 0.000 & 0.730 & 1.369 \\
\hline & $\begin{array}{l}\text { Motivation } \\
\text { excellence }\end{array}$ & or0.227 & 0.075 & 0.276 & 3.037 & 0.003 & 0.730 & 1.369 \\
\hline
\end{tabular}

Tables 4 shows that two significant variables-motivation for job and motivation for excellence, entered the regression equation and produced two models. The values of $R, R^{2}$ and adjusted $R^{2}$ in model 2 are higher than those in model 1 . The value of $\mathrm{R}^{2}$ in model 2 could explain $31.4 \%$ of learner autonomy. In Table 5 since VIF is below 10 and the tolerance is above 0 , there exists no collinearity. The values of $\beta$ in both models indicate that motivation for job has the greatest predictive power, followed by motivation for excellence.

Table 6. Multiple Step-Wise Regression Analysis of Autonomy on Motivation (1)

\begin{tabular}{lllllll}
\hline Model & $\mathrm{R}$ & $\mathrm{R}^{2}$ & Adjusted $\mathrm{R}^{2}$ & Standard Error & $\mathrm{F}$ & Sig. \\
\hline 1 & $0.665^{\mathrm{a}}$ & 0.442 & 0.437 & 0.488 & 91.030 & 0.000 \\
\hline
\end{tabular}

a. Predictors: (constant), Self-confidence.

Table 7. Multiple Regression Analysis of Autonomy on Motivation (2)

\begin{tabular}{|c|c|c|c|c|c|c|c|c|}
\hline & & \multicolumn{2}{|c|}{ Unstd coefficients } & \multicolumn{2}{|c|}{ Std coefficients } & \multirow[b]{2}{*}{ Sig. } & \multicolumn{2}{|c|}{ Collinearity statistics } \\
\hline \multicolumn{2}{|c|}{ Model } & $\mathrm{B}$ & Std errors & $\beta$ & $\mathrm{t}$ & & Tolerance & VIF \\
\hline \multirow[t]{2}{*}{1} & (constant) & 1.568 & 0.205 & & 7.631 & 0.000 & & \\
\hline & Self-confidence & 0.569 & 0.060 & 0.665 & 9.541 & 0.000 & 1.000 & 1.000 \\
\hline
\end{tabular}

Table 6 and Table 7 show the results of the influence of learner autonomy on learning motivation. Table 6 displays that only one significant variable entered the equation, that is, self-confidence. The $\mathrm{R}^{2}$ value was 0.442 , which suggests that self-confidence could explain $44.2 \%$ of learning motivation. In Table 7 both the VIF and the tolerance are 1, which indicates that there is no collinearity.

Based on the values of $\beta$ in Table 5 and Table 7, a path model was established as shown in Figure 1. 


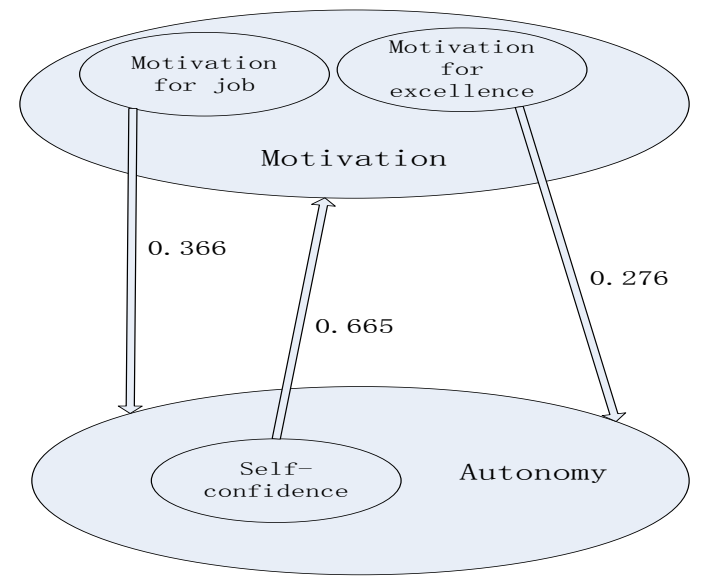

Figure 1. Path Model of Learning Motivation and Learner Autonomy

According to the model, motivation for job and motivation for excellence, as two factors of learning motivation, could effectively predict learner autonomy; self-confidence, as one factor of learner autonomy, has significant regression on learning motivation.

\section{Discussion}

From the means of the four types of motivation, it can be seen that English-major postgraduates have both intrinsic and extrinsic motivation, yet their extrinsic motivation is stronger. And motivation for job was the strongest among the four. Through correlation and regression analyses, it is found that learning motivation and perceived autonomy are positively correlated. Motivation for job and motivation for excellence can effectively predict perceived autonomy. But we cannot conclude that both intrinsic and extrinsic motivation have predictive power for perceived autonomy. For the other two types of motivation have no regression effect on autonomy, that is, one type of extrinsic motivation and one type of intrinsic motivation cannot predict perceived learner autonomy. It is partly inconsistent with the findings of $\mathrm{Li}$ and $\mathrm{Yu}(2008)$ that both intrinsic and extrinsic motivation can effectively predict learner autonomy. The study also shows that self-confidence in perceived learner autonomy has regression effect on learning motivation. This is somehow contradictory with the conclusion of Ushioda (1996) that learner autonomy can influence learning motivation.

Participants may be one causing factor. In the previous studies the participants were college students who were at a lower proficiency level and less cognitively mature while in this study our participants were more complicated in their mind and had more experience in the world. The postgraduates were grown-ups and they were more aware of the importance of employment. What's more, their immediate goal of life was much clearer, i.e., to be middle school English teachers, since motivation is often restricted or influenced by the environment that one is in (Bandura, 1986; Schunk \& Zimmerman, 2008). The participants were in a normal university and a vast majority of them were teaching in some training institutions or had a part-time job of family tutor. To put it another way, what they were doing 
in their spare time was a kind of practice or preparation for their future job. Studying to work well in their part-time job or in future job may be of their primary concern. That's why motivation for job was the strongest and most closely correlated to perceived autonomy. However, as the first-year and the second-year postgraduates, the participants were still eager to acquire more knowledge to improve themselves. They were different from the third-year postgraduates who usually care more about their job interview opportunities. Therefore, motivation for excellence was the second strongest motivation in this study.

Just because of the complicatedness of the postgraduates, we divided intrinsic motivation and extrinsic motivation further into two types respectively. The research results indicate the ineffectiveness of the intrinsic-extrinsic classification. The binary classification of motivation can explain something for younger second language learners at a lower proficiency level, but it does not work efficiently for advanced adult learners since their motivation constituents are quite different and more sophisticated. As it is not of much significance to discuss the postgraduates' binary motivation, more specific types of motivation might be considered just as in this study. To step further we'd better get rid of the restriction of the intrinsic-extrinsic or instrumental-integrative framework.

Apart from that, the relationship between self-confidence and learning motivation is worth noting. The correlation analysis shows that self-confidence had the strongest correlation with learning motivation among the four variables of perceived autonomy and the regression analysis indicates that it had great regression effect on learning motivation. Therefore, self-confidence has great influence on learning motivation, which aligns with Dörnyei (2005) who argues that self-confidence plays an important role in motivation.

\section{Conclusion}

Learning motivation and learning autonomy are two hot issues in second language learning and teaching. In the present study, postgraduates of English major as participants, four types of motivation-motivation for major, motivation for excellence, motivation for other people and motivation for job-were investigated as well as five variables of perceived autonomy. The first two types belong to intrinsic motivation while the latter two are extrinsic. It is found that all the participants had both intrinsic and extrinsic motivation but motivation for job was stronger than the other three types. Each type of motivation and perceived autonomy are positively correlated. Moreover, motivation for job and motivation for excellence have regression effect on perceived autonomy. But perceived autonomy has no regression effect on learning motivation, neither have its variables except self-confidence which can predict learning motivation. It can be followed from the results that although binary classification of motivation can be used to describe and compare the postgraduates' learning motivation but it does not work effectively and efficiently when predicting their perceived autonomy. We advocate that more specific types of motivation might be considered regardless of the intrinsic-extrinsic or instrumental-integrative framework. 
The limitation of the study lies in the sample type. All of the participants were the postgraduates in a normal university. Future studies may include participants from more universities or colleges of different types.

\section{References}

Bandura, A. (1986). Social Foundations of Thoughts and Action: A Social Cognitive Theory. Englewood Cliffs, NJ: Prentice-Hall.

Connolly, T. G., \& Sluckin, W. (1957). An Introduction to Statistics for the Social Sciences. London: Cleaver-Hume Press Ltd.

Dörnyei, Z. (2005). The psychology of the language learner: Individual differences in second language acquisition. Mahwah, NJ: Lawrence Erlbaum.

Ellis, R. (1999). The Study of Second Language Acquisition. Shanghai: Shanghai Foreign Language Education Press.

Feng, Z.-I. (2010). Education Psychology. Beijing: People's Education Press.

He, L. Z. et al. (2011). Exploring the means of developing learner autonomy in Chinese college students. Foreign Languages in China, 8(5), 18-24.

Holec, H. (1981). Autonomy in Foreign Language Learning. Oxford: Pergamon.

Li, K., \& Yu, L. M. (2008). A study on the relationship between motivation, self-efficacy, attribution and learner autonomy among college students. Foreign Language Learning Theory and Practice, $2,1-5$.

Li, L.-I. (2008). Analysis and study of the components of college freshmen's autonomy. Foreign Language World, 5, 91-96.

Navarro, D., \& Thornton, K. (2011). Investigating the relationship between belief and action in self-directed language learning. System, 39, 290-301.

$\mathrm{Ni}$, Q. Q. (2010). A case study on the correlation between motivation, learning strategies and leaner autonomy among college students. Foreign Language World, 3, 30-35.

Noels, K. A., Clement, R., \& Pelletier, L. G. (2001). Intrinsic, extrinsic, and integrative orientations of French Canadian learners of English. Canadian Modern Language Review, 57, 424-442.

Ortega, L. (2009). Understanding Second Language Education. London: Hodder Education.

Pang, G. W. (2001). On self-regulated learning. Journal of East China Normal University (Educational Sciences), 20(2), 78-83.

Qin, L.-I., \& Dai, W.-D. (2013). Constructing college English motivational self-system model in activity theory framework. Foreign Language World, 6, 23-31.

Ryan, R. M., \& Deci, E. L. (2000). Self-determination theory and the motivation of intrinsic motivation, social development, and well-being. American Psychologist, 55(1), 68-78.

Schunk, D. H., \& Zimmerman, B. J. (2008). Motivation and Self-regulated Learning: Theory, Research and Applications. New York: Lawrence Erlbaum Associates. 
Spratt, M. et al. (2002). Autonomy and motivation: Which comes first. Language Teaching Research, 6(3), 245-266.

Tanaka, M. (2013). Examining kanji learning motivation using self-determination theory. System, 41, 804-816

Ushioda, E. (1996). Developing a dynamic concept of L2 motivation. In T. Hickey, \& J. Williams (Eds.), Language, Education and Society in a Changing World (pp. 239-245). Philadelphia: Multilingual Matters.

Wu, H. Y., \& Yuan, J. L. (2012). A case study on the relationship between self-identity and learner autonomy among graduate students. Academic Degrees \& Graduate Education, 3, 63-66.

Wu, H.-Y., \& Bao, G.-Y. (2014). An empirical study of the English-major postgraduates' motivation of academic learning and their self-identity. Journal of PLA University of Foreign Languages, 37(6), 66-73.

Wu, X.-Y. (2003). Intrinsic motivation and young language learners: The impact of the classroom. System, 31, 501-517.

Xu, J. F., \& Li, B. B. (2014). The effects of learners' controllable factors on learner autonomy of college students. Modern Foreign Languages, 37(5), 647-656.

Zhao, J.-Z., \& Li, S.-S. (2014). An empirical study of college students' foreign language learning motivation. Foreign Language Research, 2, 40-45.

\section{Note}

Note 1. This study is supported by the Research Centre of Hubei Culture Dissemination Abroad in Central China Normal University [project number HBWHHWCB201604].

\section{Appendix}

\section{Part I}

1. I correctly evaluate and conclude my strengths and weaknesses in learning based on my learning conditions.

2. I make learning plans according to my learning goals.

3. I reflect and make conclusions on my learning content and learning experience.

4. I have clear goals for academic learning.

5. I know how to collect evidence to support my arguments.

6. I make detailed plans when solving complicated problems.

7. I can conclude the main arguments when reading literature.

8. I timely adjust my learning goals, plans, methods, etc.

9. I have a clear idea of my mastery of the knowledge of my major.

10. I know the structure and requirements of course paper writing.

11. I pay much attention to academic learning and spend most of my time on it. 
12. I believe that I can finally overcome difficulties and learn my major well.

13. I can tell which is more important when collecting literature.

14. I can always remove all kinds of obstacles to complete my learning plans.

15. I have confidence in solving problems through inferring and judging.

16. I first analyze the cause for the problem when encountering a problem.

17. I try to understand and learn from well-written papers when writing course papers.

18. I comprehend and memorize important concepts and content.

19. I am confident that I will be qualified for the major-related jobs after graduation.

20. I learn the knowledge of my major and know about its research status through some channels.

21. I prepare for writing course papers in advance to make sure that there is enough time to finish them.

22. I can tell sufficient and relevant evidence from insufficient and irrelevant evidence.

23. I can examine, evaluate and adjust my thinking process.

24. I use different learning methods for different learning content.

25. I question the ideas in the articles I read and form my own ideas.

\section{Part II}

26. I study as a postgraduate for better realizing the value of my life.

27. I study as a postgraduate for proving my ability.

28. I study as a postgraduate for living up to my parents' expectation.

29. I study as a postgraduate for knowing excellent people and making friends with them.

30. I study as a postgraduate for better playing my potential.

31. I study as a postgraduate for making some achievements in the area of my major.

32. I have chosen my major because of my interest in it.

33. The optional courses satisfy my need for knowledge of relevant subjects.

34. Learning the major brings me much happiness.

35. I am willing to take up jobs relevant to my major after graduation.

36. I have confidence in the employment prospect of the major I am learning.

37. I often give up hobbies for learning specialized courses.

38. I hope to be an application-multifunction talent majoring in English.

39. I study as a postgraduate because often there are experts and scholars of English major home and abroad coming to give lectures. 